\title{
Democracia Republicana Republican Democracy
}

\author{
Abril Uscanga Barradas \\ Universidad Nacional Autónoma de México \\ auscangab@derecho.unam.mx
}

DOI: https://doi.org/10.20318/eunomia.2017.3816

\begin{abstract}
Resumen
Este trabajo pretende explicar los orígenes e importancia del republicanismo como teoría aplicable a la democracia, así como su posible aplicación como una válvula de escape a la crisis democrática actual, pues últimamente se presentan numerosas y constantes críticas al sistema democrático imperante en nuestros días, lo que nos hace pensar en la existencia de una serie de deficiencias tanto políticas como sociales que, quizás, podrían ser subsanadas replanteando el modelo o visualizándolo desde otra perspectiva más acorde a los fines y necesidades de la sociedad contemporánea.
\end{abstract}

\section{Palabras clave}

Democracia republicana, libertad como no dominación, virtudes cívicas, liberalismo, crisis democrática, Estado.

\begin{abstract}
This paper aims to explain the origins and importance of republicanism as a theory applicable to democracy, as well as, its application like a scape valve of the democratic crisis that prevails today, currently, there are many criticisms of today's democratic system, which makes us think of the existence of a series of deficiencies both political and social that, maybe could be rethought or visualized from another perspective, more in line with the aims and needs of contemporary society.
\end{abstract}

\section{Keywords}

Republican democracy, liberty without domination, civic virtues, liberalism, democratic crisis, State.

SUMARIO. 1. Introducción. 2. La democracia republicana: sus inicios y consolidación 3. Republicanismo neo-ateniense 4. Republicanismo neo-romano 


\section{Introducción}

La democracia republicana se contrapone a algunos ideales de la democracia liberal, pero, sobre todo, se presenta como una salida de emergencia a las deficiencias democráticas de los Estados Constitucionales de Derecho.

Desde hace ya algún tiempo, se está debatiendo si la democracia se puede entender como el sistema político más idóneo en la actualidad, pues está evidenciando cada vez con mayor fuerza una serie de debilidades o inconsistencias (Benjamin, 2004) que hacen pensar que debe ser reformulada o, en su caso, sustituida por otra forma de gobierno, la cual bien podría ser una democracia asentada en el republicanismo.

Existen muchas preguntas que contestar respecto a esta propuesta teórica, sin embargo, nos abocaremos a contestar únicamente la pregunta: ¿A qué nos referimos cuando hablamos de republicanismo?, para así tratar de dilucidar si nos adentramos a un proyecto que promete, al menos de forma consistente, posibles soluciones a nuestra tan deslucida democracia.

\section{La democracia republicana: sus inicios y consolidación}

Resulta una tarea complicada el establecer la definición, características y fechas definitivas de teorías, ideologías o corrientes del pensamiento.

La palabra republicanismo tiene connotaciones diversas, por lo que lo dividiremos, en un primer momento, en cuatro grandes bloques:

1) el primero, correspondiente al pensamiento político del mundo antiguo ${ }^{1}$, conocido como republicanismo clásico, entendido como una tradición, un conjunto de principios y prácticas del pensamiento que se remontan a la antigua Grecia y la Roma clásica.

El republicanismo clásico tuvo sus primeras manifestaciones en Atenas con la aportación de Solón ${ }^{2}$, Clístenes ${ }^{3}$, Efialtés y Pericles ${ }^{4}$. Posteriormente se nutrió de las ideas de Polibio, Heródoto, Platón y Aristóteles, quienes estudiaron las formas de gobierno, la tendencia de las formas de gobierno a degenerarse o viciarse y la necesidad de un gobierno mixto, respectivamente (Uscanga, 2016a). En todo caso, este republicanismo que podríamos definir como clásico, fue seguido en épocas posteriores por autores como Maquiavelo (1971) o Montesquieu (1747 [2003]), por lo que su relevancia es indiscutible, $y$,

\footnotetext{
${ }^{1}$ Esta tradición acentuaba rasgos como el honor, la importancia de las virtudes cívicas, la participación política, el peligro de la corrupción, los beneficios de las constituciones mixtas y la sustitución del imperio del hombre por el imperio de la ley, la infravaloración de lo privado con respecto a la polis, el sometimiento de las mujeres, la aceptación de la esclavitud, la propensión a la guerra, la vulnerabilidad a las luchas civiles, la exhortación a la virtud, la solidaridad, la piedad, la sospecha del comercio y la exaltación de la vida pública.

${ }^{2}$ Solón hizo una distribución de las obligaciones y derechos políticos de los ciudadanos de la polis ática de acuerdo a los ingresos de la misma distribuyendo las obligaciones y derechos políticos de los ciudadanos de acuerdo a las cuatro divisiones o clases formadas.

${ }^{3}$ Clístenes perfeccionó la Constitución Soloniana a partir de la re-organización de distritos electorales atenienses, logrando una democracia atemperada debido a la conciliación que existía entre libertad y autoridad libremente aceptada.

${ }^{4}$ Estos dos últimos autores fueron parte de los líderes atenienses que promovieron las reformas contra los elementos aristocráticos -conservadores de la polis ática que tenían por objetivo darle mayor poder al pueblo llano y construir algo llamado democracia radical-.
} 
2) el segundo, relativo al periodo de republicanismo renacentista, momento en el cual se evidencia que el republicanismo clásico fue diseñado para las repúblicas de la antigüedad o las renacentistas caracterizadas por tener reducida población que permitían a los ciudadanos que se conocieran, contar con una participación política activa y directa en la gestión de la cosa pública y la preocupación por la cosa pública, lo que implicaba en último término que estaba pensada para una colectividad reducida en la que todos los habitantes tendrían un papel activo en la política.

3) el tercero sería el republicanismo revolucionario, el cual tuvo su origen en los primeros siglos de la Edad Moderna, periodo en el que predominó políticamente la monarquía absoluta hasta finales del siglo XVIII y, derivado de este absolutismo se propulsó la lucha contra este tipo de régimen, apostando por el republicanismo como sistema más deseable. En este periodo encontramos periodos de lucha y revoluciones como fue, por ejemplo, la Revolución Francesa. Los autores más destacados de esta etapas son Maquiavelo con su obra El Príncipe, en la que distinguió entre repúblicas y principados, Marsilio de Padua con el Defensor pacis; Tomás de Aquino con la Summatheologica; Bodin con Six libres de la république; Hobbes con De cive e leviathan; Locke con Two treatises on government; Rousseau con Contrat social; Kant con Rechtslehre; Hegel con Rechtsphilosophie; o Montesquieu con L'espirit des lois.

4) el cuarto, relativo a la más reciente corriente conocida como neo republicanismo o simplemente republicanismo, entendido como una doctrina política actual. Esta teoría gestó sus bases ideológicas poco antes de la década de 1970 con la publicación de tres obras que retomaron la visión republicana dentro de la discusión historiográfica para situarla como una corriente contemporánea alternativa al liberalismo ${ }^{5}$. La primera obra fue publicada en 1967 por Bernard Bailyn bajo el título The ideological origins of the American Revolution, la cual criticaba la visión liberal dominante. La segunda fue el libro de Gordon S. Wood titulado The creation of the American Republic, 1776-1787 -publicado por primera vez en 1969-, en el que se mostró al republicanismo como principio ideológico. Por último, la tercera obra se titula The machiavelliam moment; la cual fue realizada por John Pocock quien, con su publicación en 1975, hizo una propuesta de relectura del pensamiento político desde una lógica diferente a partir de una interpretación neo republicana aristotélica (Rivero, 2005: 6; Ovejero Lucas, 2003: 16- 18). Sin embargo, no fue hasta la década de 1990 cuando se presentó con más fuerza el revival republicano, respaldado en gran medida por la academia anglo-americana (Francisco, 2007: 13).

Teniendo en consideración todo lo anterior, se puede entender al republicanismo como una corriente del pensamiento político y filosófico contemporáneo que tiene como antecedente histórico remoto el pensamiento republicano clásico de la Atenas democrática, la Roma republicana, las repúblicas italianas del Renacimiento y las revoluciones democráticas.

Hoy, el republicanismo aún se encuentra en desarrollo y se presenta como una alternativa democrática al liberalismo. Presumimos, en primera instancia, que se le denomina neo republicanismo, a pesar de su evidente alejamiento de los

\footnotetext{
${ }^{5}$ En especial, al liberalismo de Rawls que constituye el resurgimiento de la filosofía política de la segunda mitad del siglo XX. Esto se origina con la publicación del libro Teoría de la justicia en 1971; en donde realiza un proyecto alternativo por fundamentar una nueva concepción de la moral, la política y el derecho que repercutirá en el desarrollo institucional de la democracia -ya que daba cabida a una concepción de justicia como equidad capaz de satisfacer por consenso las expectativas de igual libertad y justicia distributiva de la sociedad-. Véase Mejía Quintana (2010: 171).
} 
postulados clásicos, toda vez que retoma algunos aspectos de este último para reconstruirse desde la perspectiva de las sociedades contemporáneas (Ruibal, 2009: 81), es decir, se crea un revival del republicanismo antiguo a través de las diferentes etapas, siendo el republicanismo renacentista y el republicanismo revolucionario

En general se puede decir que se entiende al republicanismo como: "una tercera vía capaz de superar tanto los excesos del formalismo liberal como la cerrazón sistemática de todo tribalismo comunitario" (Villaverde, 2008: 284).

El discurso del republicanismo contemporáneo, de acuerdo a teóricos como John Maynor o Knud Haakonssen, se divide genéricamente en dos vertientes: por un lado, los teóricos inspirados en un tipo de republicanismo neo-ateniense y humanismo cívico; y por el otro lado, los inspirados en la versión neo-romana del republicanismo (Laborde y Maynor, 2008: 3).

Será importante comprender que el republicanismo no se agota en la defensa de una forma particular de Estado o gobierno, sino que comprende definiciones más amplias y sustantivas sobre el conjunto del sistema social, la economía, la cultura, la sociedad, la ciudadanía y la democracia.

Por lo anterior, podemos comprender el republicanismo desde dos perspectivas, por una parte, la postura neo romana y por otra, la postura neo ateniense.

\section{Republicanismo neo-ateniense}

El neo republicanismo ateniense también conocido como republicanismo neo aristotélico, acentúa las virtudes cívicas y la participación política como un bien intrínseco que se ha presentado en ciertas etapas del florecimiento humano.

Esta corriente del pensamiento es asociada tanto con el comunitarismo -en el que encontramos como principales expositores a Alasdair Maclntire, Charles Taylor y Michael Walzer, como con el humanismo cívico (con el que tiene algunos puntos de encuentro) -cuyas mayores figuras son Arendt, Wood y Worden-.

De acuerdo a Maynor, el republicanismo neo-ateniense ha sido retomado en algunos discursos políticos contemporáneos de filósofos como Charles Taylor (1997: 191-194), John Rawls y Sandel como una forma de revitalizar las instituciones liberales modernas. Estos autores consideran que participar en las instituciones autónomas de política democrática y cultivar las virtudes cívicas son elementos esenciales porque dan como resultado que los individuos crezcan de forma natural como seres políticos.

\section{Republicanismo neo-romano}

Por otro lado, se encuentra la vertiente que pone especial énfasis en el concepto de libertad, la cual tiene como principales teóricos a Quentin Skinner y Philip Pettit, y se caracteriza por explicar que el gobierno fue concebido para proteger a los ciudadanos contra la demagogia y tiranía.

Este pensamiento se centra en crear los mecanismos institucionales que ayuden a preservar la libertad, relevando el postulado fundamental de participación democrática del pueblo expuesto en la teoría clásica como una de las más elevadas formas del bien. 
Con base en todo lo anterior, nos encontramos ante un modelo que puede presentar buenos e importantes puntos que nos permitan revalorar elementos indispensables de los Estados democráticos, como: la libertad, especialmente en la vertiente entendida como "libertad como no dominación" y las virtudes cívicas representadas en la práctica, en cierta forma, como "Cultura de la legalidad", para asentar un sistema que vaya más allá de la democracia liberal dominante en la actualidad, la cual presenta ciertas debilidades visualizadas desde hace varias décadas. Es así que, dadas esas deficiencias, las cuales son básicamente una escasa implicación y participación política de la ciudadanía y una ineficiente representatividad, es momento de repreguntarnos si es pertinente seguir en el camino de la democracia liberal o si es momento de, a través de otras teorías, poder generar mecanismos de solución a los problemas que se presentan en los Estados Constitucionales de Derecho; especialmente, si reconocemos que los elementos que conforman nuestra democracia liberal no parecen suficientes ni desde la práctica, ni de la teoría para lograr su perfeccionamiento, superando el desánimo, la falta de interés, la resignación, la libertad con dominación, la ciudadanía sin ciudadanos comprometidos, la política sin comunidad política, la igualdad que ignora la diferencia (Uscanga, 2016b: 7), los individuos sin virtudes, entre muchos otros.

Sin duda, asegurar que éste es el momento para la puesta en marcha de la democracia republicana sería muy arriesgado, pero, aun así, será un reto y un anhelo irrenunciable el intentar perfeccionar y consolidar nuestras instituciones democráticas, tal vez a través de la introducción de nuevas teorías, como la republicana.

\section{Bibliografía}

BENJAMIN B. (2004), Democracia fuerte, trad. de Juan Jesús Mora y Boris Malmielca, Almuzara, Córdoba.

FRANCISCO, A., (2007), Ciudadanía y democracia. Un enfoque republicano, Catarata, Madrid.

LABORDE, C. y MAYNOR, J. (2008), Republicanism and political theory, Blackwell, UK.

MAQUIAVELO, N. (1971), Obras políticas, Ciencias Sociales, La Habana.

MONTESQUIEU, C. (1747) [2003], El espíritu de las leyes, Alianza, Madrid.

MEJÍA QUINTANA, Ó. (2010), Del liberalismo racional al republicanismo razonable, Universidad Nacional, Bogotá.

OVEJERO LUCAS, F. (2003). "La alternativa republicana". En: OVEJERO LUCAS, F. Nuevas ideas republicanas. Autogobierno y libertad, Barcelona, Paidós, pp 1174.

RIVERO, Á. (2005). "Republicanismo y neo republicanismo", Isegoría, núm. 33, pp. 5- 17.

RUIBAL, A. M. (2009). "El republicanismo y sus implicancias para las instituciones legales y políticas", Isonomía, núm. 30, pp. 81-100.

TAYLOR, C. (1997), Argumentos filosóficos: ensayos sobre el conocimiento, el lenguaje y la modernidad (trad. de Fina Birulés Bertrán), Paidós, Barcelona.

USCANGA BARRADAS, A. (2016), Nuevas teorías de la filosofía política: Republicanismo, Liberalismo y Comunitarismo, Tirant lo Blanch, México.

USCANGA BARRADAS, A. (2016), Deficiencias de la Democracia Liberal Contemporánea, Fontamara, México.

VILLAVERDE RICO, M. J. (2008), La ilusión republicana. Ideales y mitos, Colección Biblioteca de Historia y Pensamiento Político, Tecnos, Madrid. 